УДК 314.15:325.1-053.81

\title{
АНАЛИЗ МИГРАЦИОННЫХ ПОТОКОВ МОЛОДЕЖИ НА ТЕРРИТОРИИ СУБЪЕКТОВ РОССИЙСКОЙ ФЕДЕРАЦИИ
}

\author{
Лебедкина Надежда Сергеевна 1 , \\ nadezhda.s.lebedkina@tusur.ru \\ Александрова Юлия Константиновна², \\ jalexandrova@data.tsu.ru \\ Орлова Вера Вениаминовна', \\ orlova_vv@mail.ru \\ 1 Томский государственный университет систем управления и радиоэлектроники, \\ Россия, 634050, г. Томск, пр. Ленина, 40 \\ 2 Национальный исследовательский Томский государственный университет, \\ Россия, 634050, г. Томск, пр. Ленина, 36
}

Лебедкина Надежда Сергеевна, старший преподаватель кафедры философии и социологии Томского государственного университета систем управления и радиоэлектроники.

Александрова Юлия Константиновна, младший научный сотрудник Лаборатории наук о больших данных и проблемах общества Национального исследовательского Томского государственного университета.

Орлова Вера Вениаминовна, доктор социологических наук, профессор, заведующая кафедрой философии и социологии Томского государственного университета систем управления и радиоэлектроник.

В статье представлен анализ миграционных потоков молодых людей в возрасте до 35 лет на территории следующих субъектов Российской Федерации: Московская, Нижегородская, Воронежская, Томская, Новосибирская области, Красноярский, Хабаровский, Забайкальский и Приморский края. Обозначено, что характеристики, размещаемые пользователями в своих профилях ВКонтакте, формируют массив значимой социологической информации. Новизна заключается в определении привлекательных регионов и специфики потенциальных миграционных молодежных групп на основе данных открытых источников. Объектной сферой исследования выступает социальная сеть «ВКонтакте». Предметное поле определяется спецификой формирования миграционных потоков молодежи на основе данных открытых источников на территории субъектов Российской Федерации. Цель - изучение миграционных потоков молодых людей в возрасте до 35 лет на территории субъектов Российской Федерации Методы: метод выгрузки данных из открытых источников - при помощи открытого API «ВКонтакте» были получены данные о родном городе и текущем месте проживания пользователей. Использованы открытые обезличенные данные профилей пользователей, а также осуществлена дополнительная фильтрация аккаунтов на наличие ботов и фейковых профилей в целях валидации данных. Результаты: детально рассмотрены направления изучения активности пользователей в социальных сетях. Особое внимание уделено значимости и потенциалу использования больших данных, показана возможность дифференцировать группы пользователей по их активности в рамках технических возможностей той или иной социальной сети.

Ключевые слова: Молодежь, анализ данных, социальные сети, миграционный поток, региональные сообщества. 
Изучение миграционных процессов молодых людей представляет особый интерес не только для исследователей в области демографии и социологии, но для экономистов и органов власти. Создание условий для повышения образовательной и трудовой миграции молодежи является одним из приоритетных направлений Стратегии развития молодежи Российской Федерации на период до 2025 года. Молодые люди являются самой мобильной группой населения, и именно изучение миграционных потоков (МП) данной возрастной категории является существенным фактором, который необходимо учитывать при перспективном планировании развития регионов. Высокий уровень социально-экономического развития региона способствует перераспределению человеческих ресурсов, наращиванию человеческого капитала и его качественному росту. Миграция в целом является одним из важнейших показателей в процессе социальноэкономического развития регионов, т. к. оказывает непосредственное влияние:

- на возможность удовлетворения потребности предприятий в необходимом количестве и на требуемом уровне квалификации кадров;

- уровень безработицы - с одной стороны, может улучшить состояние рынка труда, снизив напряженность состояние рынка труда, с другой - усугубить, если в регионе отсутствует потребность предприятий в персонале;

- образовательный процесс, поскольку сильные образовательные организации привлекают молодежь и, как следствие, улучшают качество трудового потенциала региона.

Уровень культурного развития (от количества и качества пребывающего населения зависит уровень потребности в культурных благах) определяют «культурный фон» региона [1]. Согласно исследованиям Левада-центра, наибольший процент миграции был выявлен среди молодых людей, только что окончивших школу, большинство принимает решение о смене места жительства при выборе образовательного учреждения [2]. Большое влияние на процессы миграции молодежи оказала политика Министерства науки и высшего образования по повышения качества образования. С 2010 года ведется активная работа по оптимизации вузов - на 50 \% сократилось количество филиалов государственных вузов, на 20 \% - собственно высших учебных заведений, имеющих государственную аккредитацию, на $40 \%$ - негосударственных вузов и на 70 \% их филиалов [2,3]. Данные меры привели к снижению концентрации вузов на определённых территориях. На сегодняшний день есть те регионы, где вообще отсутствуют университеты (Ненецкий, Ямало-Ненецкий, Чукотский автономные округа), либо имеется только один университет (Республики Алтай, Калмыкия, Тыва, Хакасия, Магаданская и Новгородская области, Еврейская автономная область). В то же время в Москве, Санкт-Петербурге, Республике Татарстан, Новосибирской и Свердловской областях, Краснодарском крае количество университетов превышает более 10 [3]. Закрытие большей части филиалов, негосударственных образовательных учреждений, укрупнение университетов, создание научно-образовательных центров заставляют выпускников переезжать в большие города, где, как правило, более высокий уровень жизни, привлекательные условия труда и возможности карьерного роста. Данный процесс обеспечивает принимающему региону приток высококвалифицированных кадров, что, в свою очередь, негативно сказывается на уровне социально-экономического развития отдающего региона. По мнению исследователя О.В. Лешукова [4], данный процесс усиливает эффект «вымывания», который негативно сказывается и на половозрастной структуре населения в ряде регионов. Больше остальных страдают регионы, не имеющие возможности предоставить молодым специалистам конкурентоспособные рабочие места. Нельзя не согласиться с тем фактом, что данный процесс сильно сказывается на эконо- 
мике региона, но если региональный рынок труда окажется привлекательным и выпускники смогут вернуться в свой город, то данный процесс не повлечет явных рисков. Выявление миграционных установок молодых людей является одним из важных аспектов в вопросах управления МП в регионе.

В большинстве западных стран изучению МП молодых людей уделяется очень большое внимание. Проведение переписи населения и данные административных регистров позволяют получить не только обширную статистику, но и детально проследить направление миграции [5]. В России большинство исследований связано с образовательной миграцией, но в связи с особенностью сбора данных до 2011 года студенты, имеющие временную регистрацию на территории субъекта, в статистику региона не попадали, что, конечно же, искажало реальную картину [6, 7].

\section{Методология исследования}

Сбор данных в социальной сети «ВКонтакте» осуществлялся с помощью АРІ (applicationprogramminginterface). API упрощает создание кода, поскольку предоставляет набор готовых классов, функций или структур для работы с имеющимися данными. API ВКонтакте - это интерфейс, который позволяет получать информацию из базы данных vk.com с помощью http-запросов к специальному серверу. Большим преимуществом данного метода является то, что для получения данных не нужно знать в подробностях, как устроена база, из каких таблиц и полей каких типов она состоит - достаточно того, что API-запрос об этом «знает». Синтаксис запросов и тип возвращаемых ими данных строго определены на стороне самого сервиса. Users.get - название метода API ВКонтакте. Методы представляют собой условные команды, которые соответствуют той или иной операции с базой данных - получение информации, запись или удаление. Например, users.get - метод для получения информации о пользователе (имя, фамилия, пол, город, статус, место учебы/работы и т. д.) $[8,9]$.

С помощью метода getSubscriptions можно получить список идентификаторов сообществ, на которые подписан пользователь, и по этим идентификаторам уже можно запросить информацию о самом сообществе (название, описание, количество участников и т. д.). Помимо этого, АРІ ВКонтакте включает в себя методы для получения данных со стены сообщества или со стены пользователя, фотографий, времени, когда пользователь находится онлайн и многое другое [10, 11].

В рамках исследования фокус интереса авторов направлен на изучение анализ МП молодых в людей в возрасте до 35 лет на территории следующих субъектов Российской Федерации: Московская, Нижегородская, Воронежская, Томская, Новосибирская области, Красноярский, Хабаровский, Забайкальский и Приморский края.

С развитием информационных технологий изучение, анализ, прогнозирование различных социальных процессов стало возможно на основе данных цифровых следов пользователей, без применения традиционных методов [12-14]. При изучении МП молодых людей в возрасте до 35 лет на территории Московской, Нижегородской, Воронежской, Томской, Новосибирской областей, Красноярского, Хабаровского, Забайкальского и Приморского краев была произведена выгрузка данных 2000 профилей пользователей ВКонтакте. Эта социальная сеть является наиболее популярной в России: по данным Mediascope, соцсеть «ВКонтакте» входит в топ-10 самых популярных ресурсов в России, количество пользователей «ВКонтакте» в России составляет более 73 млн [15]. На основе идентификационных маркеров пользователей, такие как возраст и миграция (переезд из одного населенного пункта в другой), была сформирована электронная база данных с результатами эмпирического исследования. В ходе проведения ис- 
следования был проведен качественный и количественный анализ результатов с применением методов математической статистики, включающий в себя следующие критерии:

- МП 1 - живет в родном городе;

- МП 2 - переехал из родного города в город анализируемого региона;

- МП 3 - переехал из родного города в другой город, но имеет подписки в регистрируемых сообществах анализируемого региона.

Помимо этого получены количественные значения пользователей по критериям:

- миграции;

- полового признака;

- возраста.

В исследовании были использованы только открытые обезличенные данные профилей пользователей, а также осуществлена дополнительная фильтрация аккаунтов на наличие ботов и фейковых профилей в целях валидации данных.

\begin{tabular}{|c|c|c|c|c|c|c|}
\hline \multicolumn{7}{|c|}{$\begin{array}{c}\text { Московская область } \\
\text { Moscow region }\end{array}$} \\
\hline \multirow{7}{*}{$\begin{array}{r}50,0 \% \\
40,0 \% \\
30,0 \% \\
20,0 \% \\
10,0 \% \\
0,0 \%\end{array}$} & & & & & & \\
\hline & & & & & & \\
\hline & & & & & & \\
\hline & & & & & & \\
\hline & & & & & & \\
\hline & & & & & & \\
\hline & $\begin{array}{c}\text { девушки } \\
18-22 \\
\text { лет/girls } \\
18-22 \\
\text { years old }\end{array}$ & $\begin{array}{c}\text { девушки } \\
\text { 18-35 } \\
\text { лет/girls } \\
\text { 18-35 } \\
\text { years old }\end{array}$ & $\begin{array}{c}\text { девушки } \\
\text { младше } \\
17 \text { лет girls } \\
\text { under } 17 \\
\text { years old }\end{array}$ & $\begin{array}{c}\text { юноши } \\
18-22 \text { года } \\
\text { young men } \\
18-22 \\
\text { years old }\end{array}$ & $\begin{array}{c}\text { юноши } \\
18-35 \text { лет } \\
\text { young men } \\
18-35 \\
\text { years old }\end{array}$ & $\begin{array}{c}\text { юноши } \\
\text { младше } \\
17 \text { лет } \\
\text { yound } \\
\text { men under } \\
17 \text { years } \\
\text { old }\end{array}$ \\
\hline $\begin{array}{c}\text { - Миграция не идентифицирована } \\
\text { Migration not identified }\end{array}$ & $0,4 \%$ & $0,2 \%$ & $0,6 \%$ & $0,4 \%$ & $0,3 \%$ & $0,6 \%$ \\
\hline $\begin{array}{l}\text { घиграционный поток 1/Migration } \\
\text { stream } 1\end{array}$ & $57,1 \%$ & $58,3 \%$ & $55,7 \%$ & $52,1 \%$ & $55,7 \%$ & $51,7 \%$ \\
\hline $\begin{array}{l}\text { चиграционный поток 2/Migration } \\
\text { stream } 2\end{array}$ & $31,6 \%$ & $32,9 \%$ & $35,6 \%$ & $34,4 \%$ & $33,1 \%$ & $36,3 \%$ \\
\hline $\begin{array}{l}\text { Миграционный поток 3/Migration } \\
\text { stream } 3\end{array}$ & $10,9 \%$ & $8,6 \%$ & $8,1 \%$ & $13,0 \%$ & $10,9 \%$ & $11,5 \%$ \\
\hline
\end{tabular}

Pис. 1. Движение населения молодежного возраста на территории Московской области, \%

Fig. 1. Movement of the population of youth in the territory of the Moscow region

Оценивая территориальное перемещение молодых людей в возрасте до 35 лет на территории Московской области (рис. 1), МП 1 («живет в родном городе») по всем возрастным категориям превышает $50 \%$, что означает, что более половины респондентов проживают в родном городе. Наибольший процент был получен среди девушек в возрасте 18-35 лет. МП 2 имеет средний показатель около $34 \%$, наибольший результат 
(36,3 \%) у возрастной группы парней младше 17 лет, чуть ниже $(35,6 \%)$ у девушек той же возрастной группы, наименьшее значение (31,6 \%) было получено у возрастной группы девушек в возрасте 18-22 лет. МП 3 получил наименьшее распространение среди всех возрастных групп: самый низкий показатель у девушек в возрасте до 17 лет, чуть выше - у возрастной группы 18-35, показавших наивысшее значение в МП 1, самый высокий результат был выявлен у парней в возрасте 18-35 лет. Полученные результаты позволяют сделать вывод, что уровень оттока населения на территории Московской области достаточно низкий, что может косвенно свидетельствовать о том, что уровень социально-экономического развития региона достаточно высок и большая часть населения не стремится его покидать.

\begin{tabular}{|c|c|c|c|c|c|c|}
\hline \multirow{8}{*}{$\begin{array}{r}50,0 \% \\
40,0 \% \\
30,0 \% \\
20,0 \% \\
10,0 \% \\
0,0 \%\end{array}$} & \multicolumn{6}{|c|}{$\begin{array}{l}\text { Нижегородская область } \\
\text { Nizhny Novgorod Region }\end{array}$} \\
\hline & & & & & & \\
\hline & & & & & & \\
\hline & & & & & & \\
\hline & & & & & & \\
\hline & & & & & & \\
\hline & & & & & & \\
\hline & $\begin{array}{c}\text { девушки } \\
\text { 18-22 } \\
\text { лет/girls } \\
18-22 \\
\text { years old }\end{array}$ & $\begin{array}{c}\text { девушки } \\
18-35 \\
\text { лет/girls } \\
18-35 \\
\text { years old }\end{array}$ & $\begin{array}{c}\text { девушки } \\
\text { младше } \\
17 \\
\text { лет/girls } \\
\text { under } 17 \\
\text { years old }\end{array}$ & $\begin{array}{c}\text { юноши } \\
18-22 \\
\text { лет/youn } \\
\text { g men } \\
18-22 \\
\text { years old }\end{array}$ & $\begin{array}{c}\text { юноши } \\
18-35 \\
\text { лет/youn } \\
\text { g men } \\
18-35 \\
\text { years old }\end{array}$ & $\begin{array}{c}\text { юноши } \\
\text { младше } \\
17 \\
\text { лет/boys } \\
\text { under } 17 \\
\text { years old }\end{array}$ \\
\hline $\begin{array}{l}\text { - Миграция не идентифицирована } \\
\text { Migration not identified }\end{array}$ & $0,2 \%$ & $0,1 \%$ & $0,2 \%$ & $0,1 \%$ & $0,1 \%$ & $0,2 \%$ \\
\hline $\begin{array}{c}\text { Миграционный поток 1/Migration } \\
\text { stream } 1\end{array}$ & $60,7 \%$ & $59,7 \%$ & $53,9 \%$ & $56,8 \%$ & $59,8 \%$ & $52,6 \%$ \\
\hline $\begin{array}{c}\text { Миграционный поток 2/ Migration } \\
\text { stream } 2\end{array}$ & $29,5 \%$ & $32,6 \%$ & $40,6 \%$ & $31,2 \%$ & $29,7 \%$ & $40,4 \%$ \\
\hline $\begin{array}{c}\text { Миграционный поток 3/Migration } \\
\text { stream } 3\end{array}$ & $9,6 \%$ & $7,7 \%$ & $5,2 \%$ & $11,9 \%$ & $10,4 \%$ & $6,8 \%$ \\
\hline
\end{tabular}

Pис. 2. Движение населения молодежного возраста на территории Нижегородской области, \%

Fig. 2. Movement of the population of youth in the territory of the Nizhny Novgorod region

При проведении анализа миграции на территории Нижегородской области (рис. 2), наиболее высокий показатель у МП 1 выявлен среди следующих возрастных категорий: девушки 18-22 лет (60,7 \%), девушки 18-35 лет (59,7 \%) и парни 18-35 лет $(59,8 \%)$. Наименьшие результаты зафиксированы у парней младше 17 лет и составили $52,6 \%$, чуть выше значение - у девушек в возрасте младше 17 лет - 53,9 \%. В МП 2 наивысший показатель зафиксирован у девушек $(40,6 \%)$ и юношей $(40,4 \%)$ в возрастной группе младше 17 лет. Остальные возрастные группы показали примерно одинаковый результат: территориальное перемещение среди девушек в возрасте 18-35 лет со- 
ставляет 32,6 \%, у парней в возрасте 18-35 лет - $29 \%$ и девушек в возрасте от 18-22 лет - 29,5\%. МП 3 имеет самые низкие результаты: наивысший результат среди юношей возрастной категории 18-22 лет (11,9\%), чуть ниже результат выявлен у парней в возрасте 18-35 лет (10,4 \%). Самая низкая величина в данном МП у девушек в возрасте младше 17 лет, парни данной возрастной категории имеют более высокий показатель $(6,8 \%)$, но он ниже, чем у других возрастных групп. Среди девушек в возрасте 18-22 лет он составил 9,6 \% и 7,7\% - у девушек 18-35 лет.

Данные результаты позволяют сделать вывод, что на территории Нижегородской области достаточно низкий уровень миграции и практически 60 \% населения проживают в родном городе, молодежь не имеет особых стремлений покинуть родной город. В целом данный регион демонстрирует стабильные показатели [14].

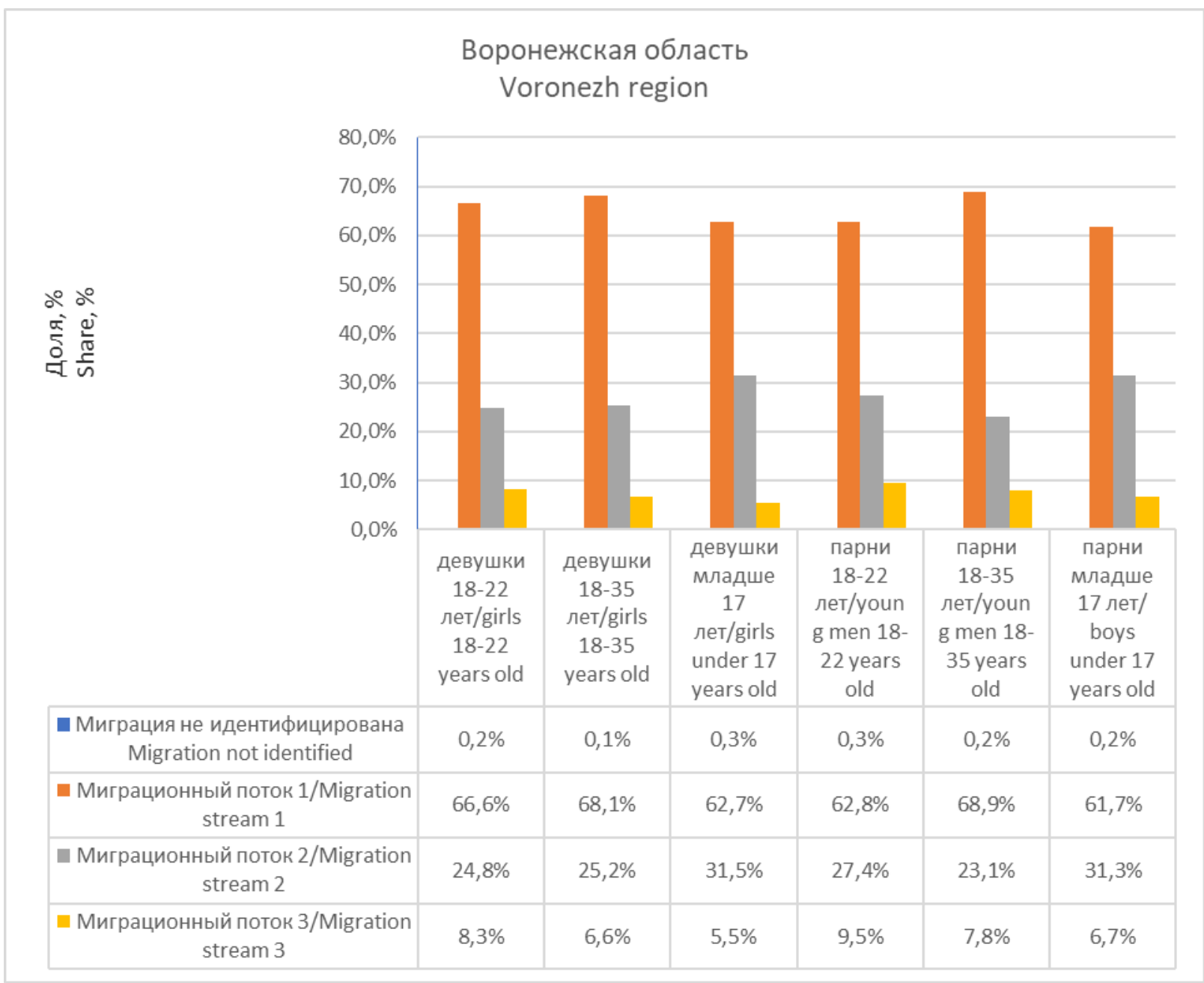

Pис. 3. Движение населения молодежного возраста на территории Воронежской области, \%

Fig. 3. Movement of the youth population in the Voronezh region

По результатам исследования Воронежская область (рис. 3) имеет самые высокие значения по количеству молодых людей, выбирающих для проживания родной город. МП 1 в Воронежской области - один из самых высоких уровней, по сравнению с другими исследуемыми регионами. Наибольший показатель выявлен среди юношей 18-35 лет $(68,9 \%)$, чуть ниже $(68,1 \%)$ у девушек той же возрастной категории, 
наименьший - в МП 1 у парней младше 17 лет, практически такие же результаты у девушек той же возрастной категории (62,7 \%) и парней 18-22 лет. Данные результаты свидетельствуют об очень низком уровне миграции коренного населения. В МП 2 практически у всех возрастных групп значение индикатора практически не превышено 30 \%. Результаты среди всех возрастных групп в МП 3 не превысили $10 \%$, что может свидетельствовать о низком оттоке коренного населения и невысокой миграционной активности в данном регионе.

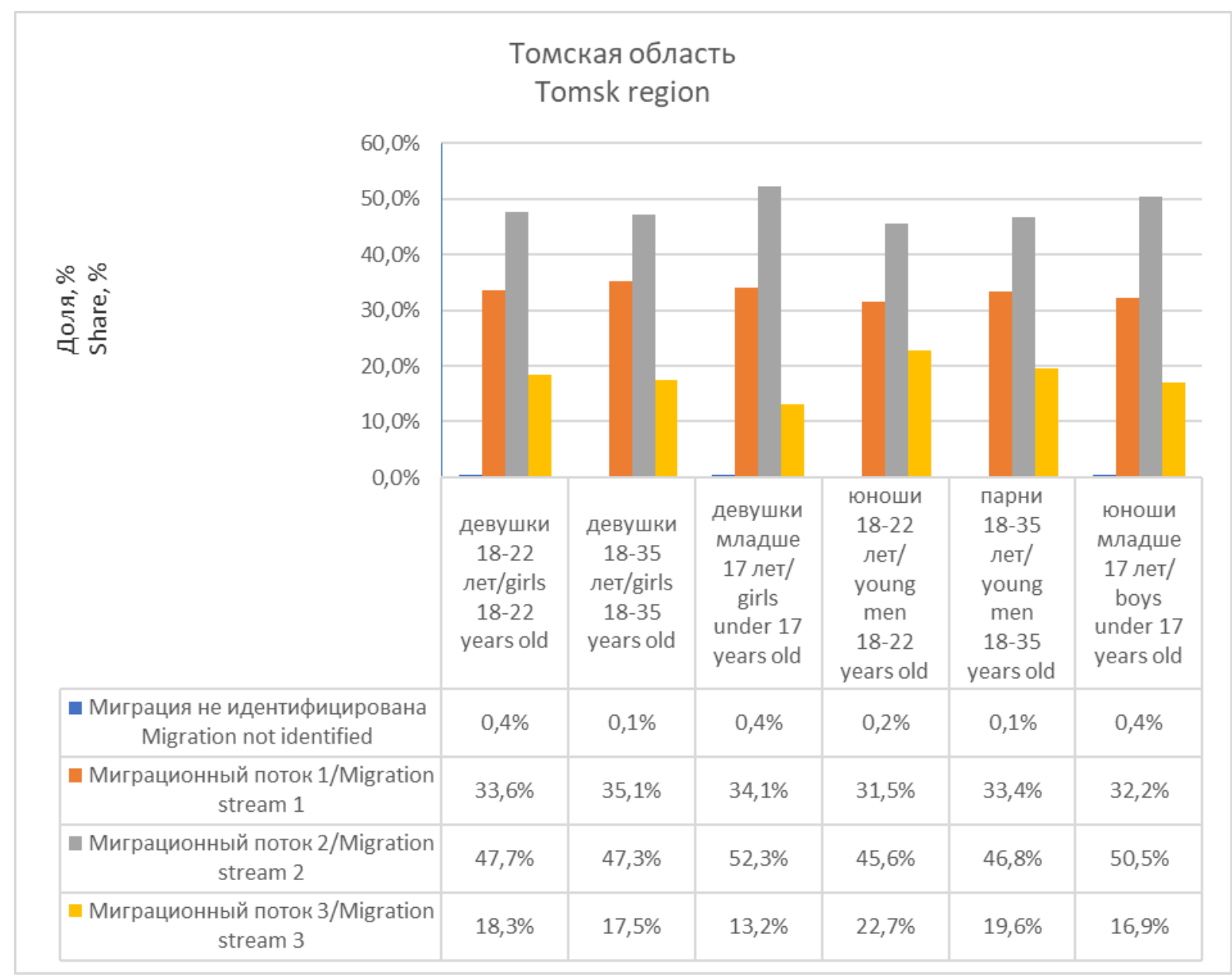

Pис. 4. Движение населения молодежного возраста на территории Томской области, \%

Fig. 4. Movement of the youth population on the territory of the Tomsk region

На территории Томской области (рис. 4), в отличие от всех других исследуемых регионов, в МП 1 по всем возрастным группам показатель в среднем составил 33,5 \%, в отличие от МП 2, где среднее значение 48,4 \%. Наивысший - у возрастной группы девушек младше 17 лет (52,3 \%), наименьший - среди парней в возрасте 18-22 лет (45,6 \%). Остальные возрастные группы имеют результаты около $47 \%$. МП 3 отмечает также отличные результаты, по сравнению с другими исследуемыми регионами: наименьший уровень у возрастной группы девушек младше 17 лет составил 13,2 \%, являясь при этом самым высоким по сравнению с другими регионами. Наивысший показатель выявлен у парней 18-22 лет. По результатам исследования можно сделать вывод, что в Томской области высокий уровень миграции: уровень населения, приехавшего из дру- 
гих городов, составляет более $45 \%$. Следует отметить высокий процент оттока постоянного населения в другие регионы. Такую миграционную активность населения необходимо связать в первую очередь с тем, что Томская область является одним из крупнейших образовательных центров России, что и обеспечивает постоянный приток и отток населения. Основываясь на самых высоких, по сравнению с другими регионами, значениях МП 3, можно сделать вывод, что Томская область является неким «перевалочным» пунктом, где молодые люди проживают, пока получают образование, но дальнейшую жизнь с данным регионом не связывают и не остаются здесь в качестве трудового ресурса.

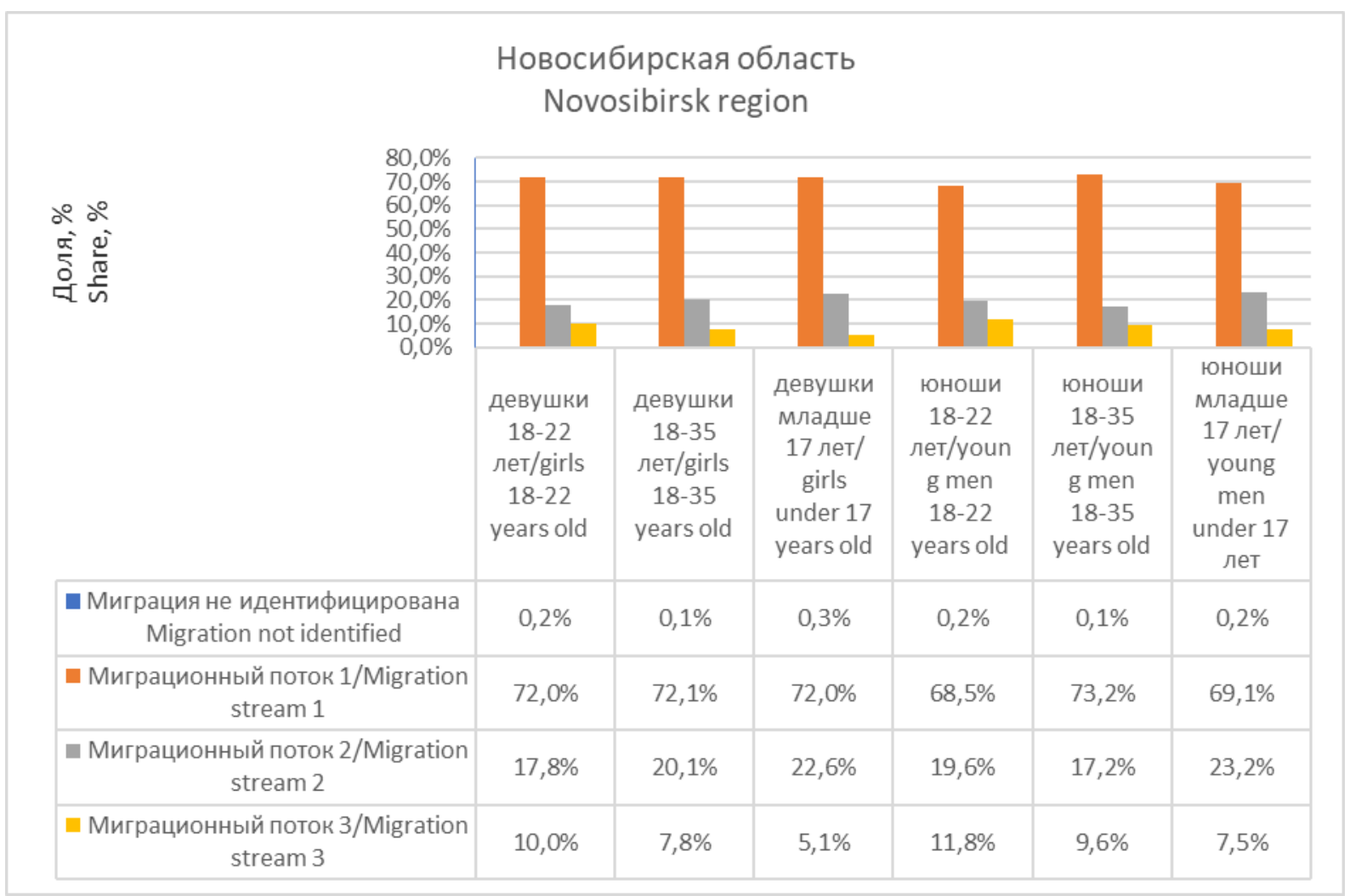

Pис. 5. Движение населения молодежного возраста на территории Новосибирской области, \%

Fig. 5. Movement of the population of youth in the territory of the Novosibirsk region

Новосибирская область имеет наивысший процент населения, проживающего в родном городе. По всем возрастным категориям он составляет практически 70 \%. Также Новосибирская область демонстрирует самые низкие показатели МП 2 - наивысшим он является в возрастной группе парней младше 17 лет $(23,2 \%)$, наименьший уровень у возрастной группы парней в возрасте 18-35 лет (17,2 \%). МП 3 в среднем выражено значение, как и в других исследуемых регионах, за исключением Томской области. Можно сделать вывод, что в Новосибирской области средний достаточно низкий уровень миграционной активности: практически 70 \% постоянного населения проживает в родном городе и не стремится его покидать, что обеспечивает стабильную демографическую ситуацию, но, с другой стороны, Новосибирская область не является привлекательным для мигрантов регионом. 


\begin{tabular}{|c|c|c|c|c|c|c|}
\hline \multicolumn{7}{|c|}{$\begin{array}{l}\text { Красноярский край } \\
\text { Krasnoyarsk Territory }\end{array}$} \\
\hline \multirow{7}{*}{$\begin{array}{r}30,0 \% \\
20,0 \% \\
10,0 \% \\
0,0 \%\end{array}$} & & & & & & \\
\hline & & & & & & \\
\hline & & & & & & \\
\hline & & & & & & \\
\hline & & & & & & \\
\hline & & & & & & \\
\hline & $\begin{array}{c}\text { девушки } \\
\text { 18-22 } \\
\text { лет/girls } \\
\text { 18-22 } \\
\text { years old }\end{array}$ & $\begin{array}{c}\text { девушки } \\
18-35 \\
\text { лет/girls } \\
\text { 18-35 } \\
\text { years old }\end{array}$ & $\begin{array}{c}\text { девушки } \\
\text { младше } \\
17 \text { лет/ } \\
\text { girls } \\
\text { under } 17 \\
\text { years old }\end{array}$ & $\begin{array}{c}\text { юноши } \\
18-22 \\
\text { лет/boys } \\
18-22 \\
\text { years old }\end{array}$ & $\begin{array}{c}\text { юноши } \\
18-35 \\
\text { лет/boys } \\
18-35 \\
\text { years old }\end{array}$ & $\begin{array}{c}\text { юноши } \\
\text { младше } \\
17 \text { лет/ } \\
\text { boys } \\
\text { under } 17 \\
\text { years old }\end{array}$ \\
\hline $\begin{array}{c}\text { - Миграция не идентифицирована } \\
\text { Migration not identified }\end{array}$ & $0,1 \%$ & $0,1 \%$ & $0,3 \%$ & $0,3 \%$ & $0,1 \%$ & $0,3 \%$ \\
\hline $\begin{array}{l}\text { - Миграционный поток 1/Migration } \\
\text { stream } 1\end{array}$ & $60,4 \%$ & $61,6 \%$ & $52,2 \%$ & $57,2 \%$ & $62,9 \%$ & $52,6 \%$ \\
\hline $\begin{array}{c}\text { - Миграционный поток 2/Migration } \\
\text { stream } 2\end{array}$ & $29,6 \%$ & $30,8 \%$ & $41,8 \%$ & $30,7 \%$ & $27,6 \%$ & $38,6 \%$ \\
\hline $\begin{array}{l}\text { Миграционный поток 3/Migration } \\
\text { stream } 3\end{array}$ & $9,9 \%$ & $7,6 \%$ & $5,7 \%$ & $11,8 \%$ & $9,3 \%$ & $8,5 \%$ \\
\hline
\end{tabular}

Pис. 6. Движение населения молодежного возраста на территории Красноярского края, \%

Fig. 6. Movement of the youth population in the Krasnoyarsk Territory

Рассматривая миграционную траекторию населения Красноярского (рис. 6), можно сделать вывод, что большая часть населения все же является коренным и проживает по месту рождения. Наивысший показатель среди парней в возрасте 18-35 лет, практически такой же $(61,6 \%)$ у девушек той же возрастной группы. Самые низкие значения (52,2 \%) выявлены у девушек младше 17 лет и парней той же возрастной категории $(52,6 \%)$. МП 2 показывает практически средние результаты по сравнению с другими регионами, за исключением Томской и Новосибирской областей. Наивысшей результат обнаружен в возрастной группе девушек в возрасте младше 17 лет (41,8 \%). Он значительно превалирует у старших возрастных групп: 29,6 \% девушек 18-22 лет, 27,9 \% парней 18-35 лет. МП 3 показывает средние результаты среди других исследуемых регионов, за исключением Томской области и Забайкальского края. Наивысший уровень выявлен в возрастной группе парней 18-22 лет (11,8\%), у девушек той же возрастной категории показатель составил 9,9 \%, наименьшее значение - у девушек в возрасте до 17 лет $(5,7 \%)$, среди парней данной возрастной категории данный индикатор значительно выше и составил $8,5 \%$. 


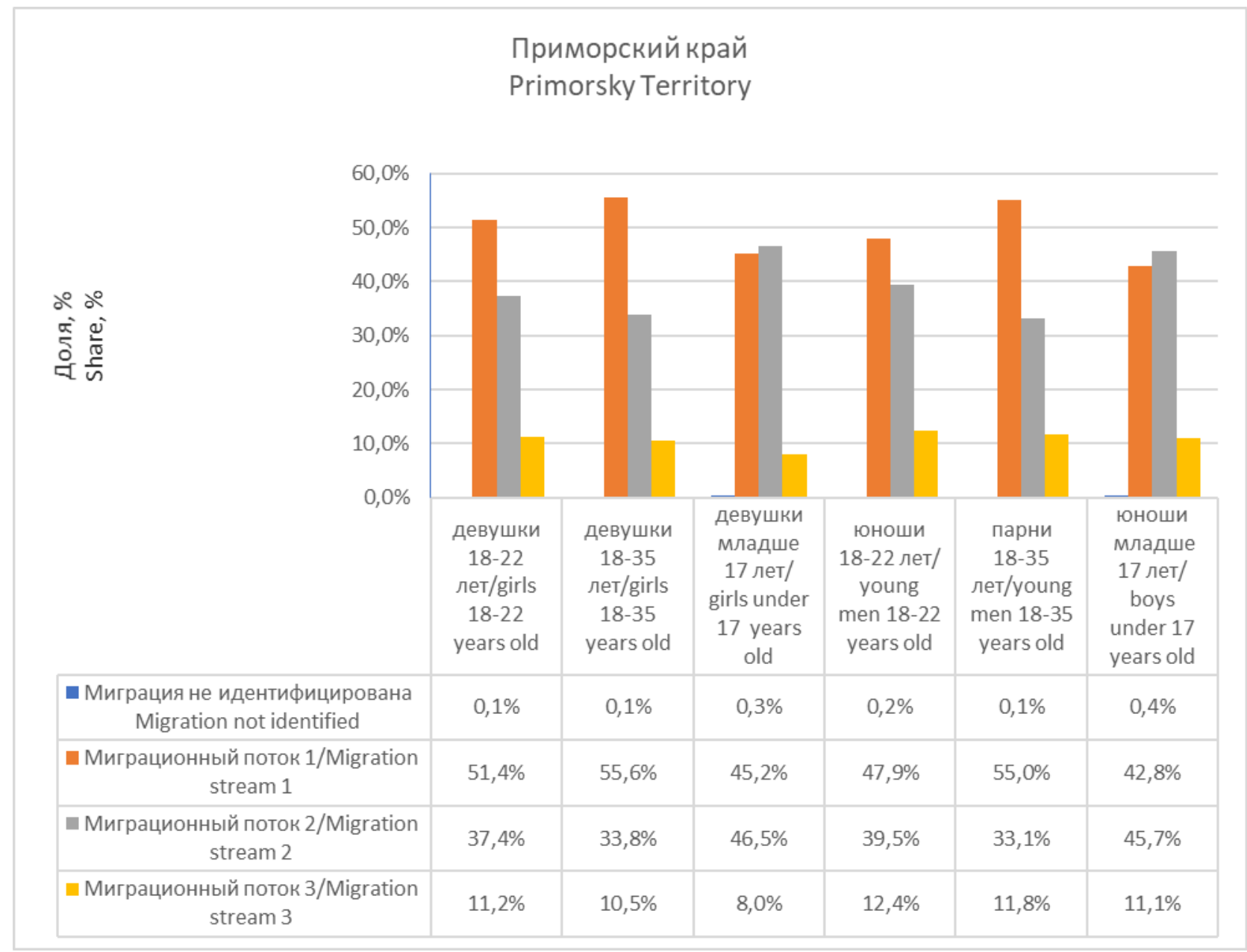

Puс. 7. Движение населения молодежного возраста на территории Приморского края, \%

Fig. 7. Movement of the youth population in the Primorsky Territory

На территории Приморского края МП 1 и МП 2 по нескольким возрастным группам имеют достаточно близкие показатели. Среди других исследуемых регионов такой результат обнаружен не был. Количество коренного населения, проживающего на территории Приморского края, не превышает 55,6 \%: самый высокий - выявлен у возрастной категории девушек 18-35 лет (55,6 \%) и парней той же возрастной категории (55 \%). Самый низкий уровень 42,8 \% идентифицирован у парней младше 17 лет. МП 2 имеет наивысшие показатели у возрастных групп девушек младше 17 лет (46,5\%) и парней той же возрастной категории $(45,7 \%)$, наименьшее значение среди девушек и парней 18-35 лет - 33,8 и 33,1 \% соответственно. МП 3 практически по всем возрастным группам показывает $11 \%$ и выше: наименьший уровень проявляется у девушек младше 17 лет (8 \%). Относительно небольшая разница между МП 1 и МП 2 является уникальной среди исследуемых регионов, может свидетельствовать о привлекательности данного региона для мигрантов $[15,16]$.

На территории Хабаровского края (рис. 8) МП 1 практически по всем возрастным категориям составляет более 55 \%. Наивысшее значение у возрастной категории 18-35 лет, как у парней и так у девушек, составляет более $61 \%$, наименьший показатель выявлен среди парней младше $17-54,8 \%$. МП 2 имеет средний уровень по отношению к другим исследуемым регионам за исключением Томской области. Наивысший показатель 
у девушек младше 17 лет (35,7 \%), наименьший - у парней в возрасте 18-35 лет, у девушек данной возрастной группы данный индикатор составил 28 \%. В МП 3, только две возрастные группы имеют отличные результаты: 8,4 \% - у возрастной группы девушек младше 17 лет, а наивысший - у возрастной категории парней 18-22 лет (13\%). У девушек в возрасте 18-35 лет величина составила 10,3 \%, у остальных категорий 11,1-11,5 \%. По результатам можно сделать вывод, что миграционная активность в Хабаровском крае достаточно активная.

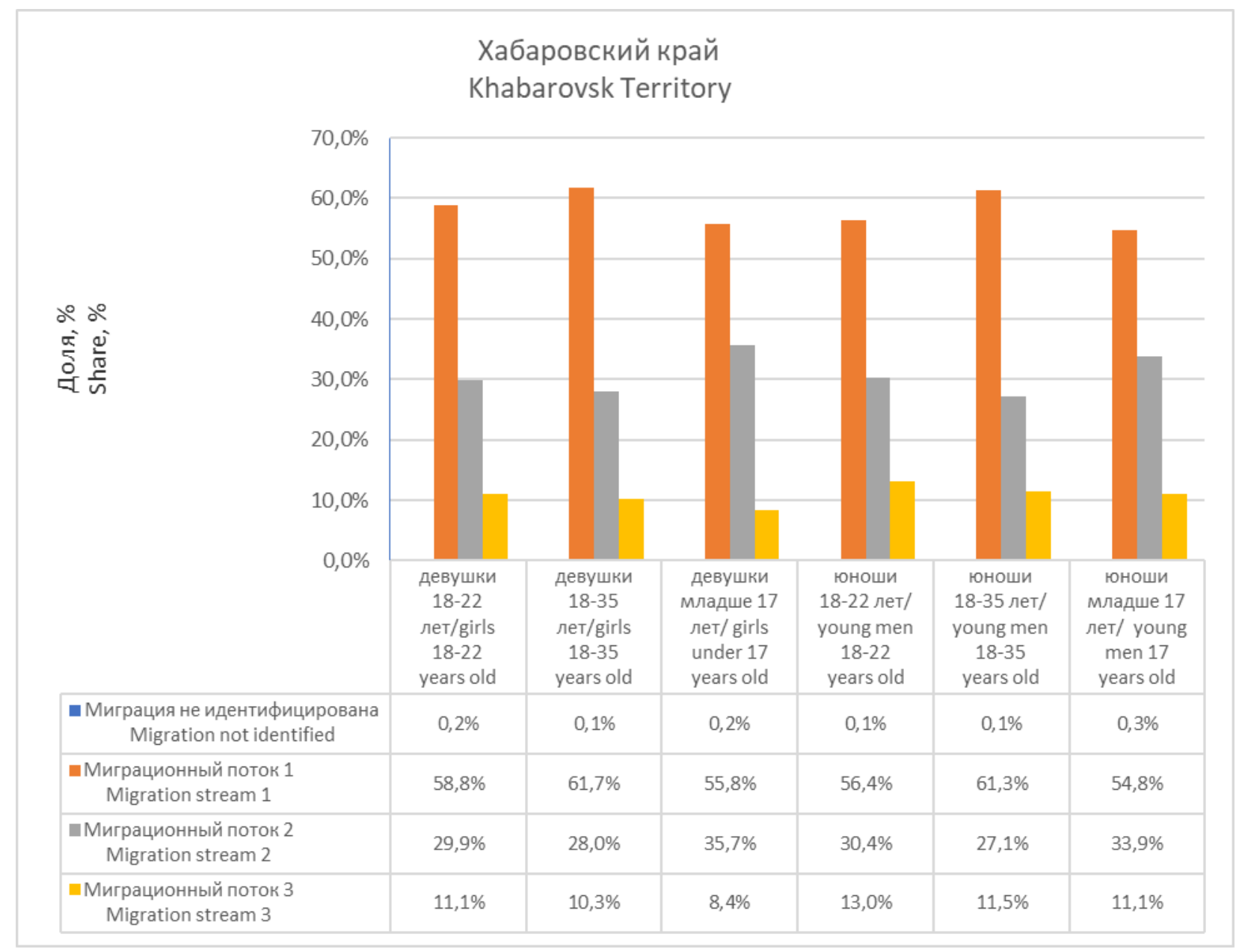

Pис. 8. Движение населения молодежного возраста на территории Хабаровского края, \%

Fig. 8. Movement of the youth population in the Khabarovsk Territory

В целом исследование показало относительную устойчивость постоянного населения (рис. 10). В среднем у всех возрастных групп показатель составил более 57 \%, наименьший - выявлен среди парней младше 17 лет (53,9\%), наивысший уровень $60 \%$ зафиксирован у девушек 18-35 лет. МП 2 в среднем по всем регионам имеет показатели свыше 30 \%. Наивысший результат зафиксирован среди девушек и юношей младше 17 лет - 36,3 и 36 \% соответственно, наименьший результат был у девушек 18-22 лет (30,1 \%) и парней 18-35 лет (30,5 \%). Результаты по МП 3 могут показывать относительно невысокий \% оттока постоянного населения, в среднем по всем возрастным группам он не превышает $10 \%$ : наименьший - обнаружен у девушек младше 17 лет (6,9 \%), наивысший - у парней 18-22 лет (12,6\%). 


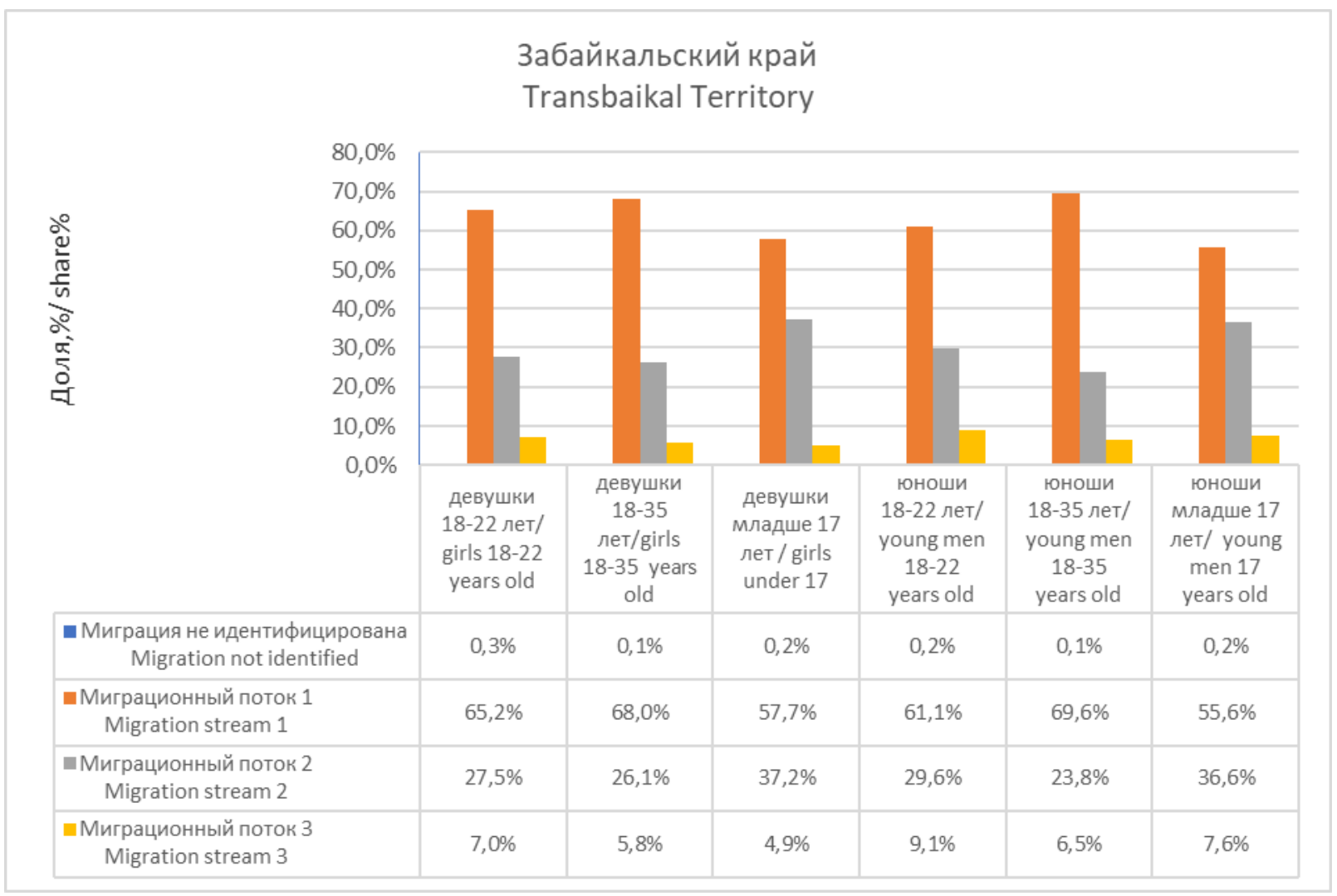

Pис. 9. Движение населения молодежного возраста на территории Забайкальского края, \%

Fig. 9. Movement of the youth population in the territory of the Transbaikal Territory

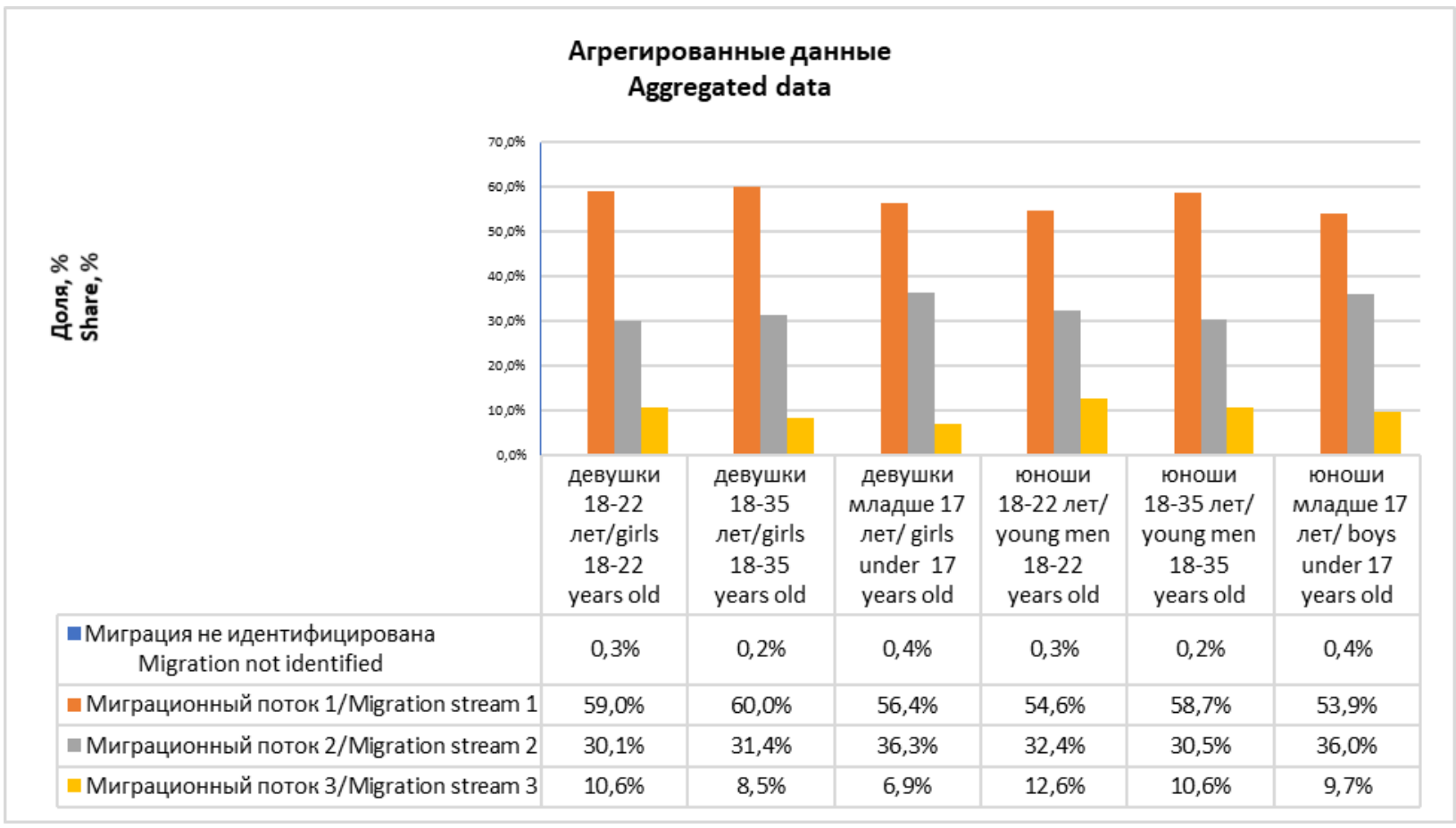

Pис. 10. Агрегированные данные МП, \%

Fig. 10. Aggregated data of migration flows 


\section{Выводы}

Необходимо отметить, что использование цифровых методов, современных инструментов и данных из открытых источников в сочетании с традиционными методами (например, опросными) позволит обогатить возможности изучения формирования сообществ, интересов молодежи, МП, преимуществ и рисков процессов, происходящих в социальных сетях.

В процессе исследования детально рассмотрены направления изучения активности пользователей в социальных сетях. Отдельное внимание уделено значимости и потенциалу использования больших данных, благодаря которым можно дифференцировать группы пользователей по их активности в рамках технических возможностей той или иной социальной сети.

В рамках исследования фокус интереса был направлен на изучение сообществ социальных сетей в сети «ВКонтакте» Центрального, Сибирского и Дальневосточного федеральных округов, в том числе политических интересов, МП. В ходе исследования было выделено несколько возрастных групп, пользователей, состоящих в региональных сообществах, также проведен анализ МП.

Работа выполнена при финансовой поддержке РФФИ 20-011-31154 опн.

\section{СПИСОК ЛИТЕРАТУРЫ}

1. Половинко В.С. Анализ миграционных установок молодежи г. Омска // Экономика и управление народным хозяйством. - 2016. - № 11 (144). - С 43-46.

2. Галанина Е.В., Акчелов Е.О. А Potentia ad actum: виртуальный мир видеоигры // Исторические, философские, политические и юридические науки, культурология и искусствоведение. Вопросы теории и практики, 2016. - № 12 (74). - Ч. 3. - С. 45-51.

3. Кашницкий И.С., Мкртчян Н.В., Лешуков О.В. Миграция молодежи в России // Демоскоп Weekly. URL: http://www.demoscope.ru/weekly/2016/0703/demoscope703.pdf (дата обращения 13.01.2021).

4. Ульмясбаева А.О. Современные тенденции межрегиональной образовательной миграции российской молодежи // Теория и практика общественного развития. URL: http://teoriapractica.ru/rus/files/arhiv_zhurnala/2020/12/sociology/ulmyasbaeva.pdf (дата обращения: 13.01.2021)

5. Лешуков О.В., Лисюткин М.А. Тенденции развития системы высшего образования в Москве / Высшее образование сегодня. - 2013. - № 10. - С. 6-17.

6. Численность и миграция населения Российской Федерации в 2017 году // Федеральная служба государственной статистики. URL: https://www.gks.ru/bgd/regl/b18_107/Main.htm (дата обращения 13.01.2021).

7. Габдрахманов Н.К. Концентрация студентов в системе высшего образования на карте Российской Федерации // Вестник Российского университета дружбы народов. Серия «Экономика». - 2019. Т. 27. - № 1. - С. 7-17.

8. Габдрахманов Н.К. Молодежная миграция как индикатор региональной аттрактивности // Географический вестник. - 2020. - Т. 1. - № 52. - С. 96-107.

9. Шарова Е.Н. Миграционные установки молодежи Мурманской области // Проблемы развития территорий. -2015 . - № 77. - С. 88-103.

10. Киселева А.М. Региональные миграционные процессы: особенности и проблемы (на примере Омской области) // Социология и общество: социальное неравенство и социальная справедливость: материалы V Всероссийского социологического конгресса. - М.: Рос. Об-во социологов, 2016. C. $1212-1225$.

11. Becker G. S. Investment in human capital: a theoretical analysis // Journal of Politikal Economy. - 1962. V. 70. - P. 9-49. URL: https://www.semanticscholar.org/paper/Investment-in-Human-Capital\%3A-ATheoretical-Analysis-Becker/1cb85895dbeb216ac78721a2239f012f8e8a9167 (дата обращения 13.01.2021).

12. Беккер Г.С. Человеческое Поведение: экономический подход. - М.: ГУВШЭ, 2003. - 672 с.

13. Зайончковская Ж.А. Миграционная ситуация в регионах России. Вып. 1: Приволжский федеральный округ // Сборник. Центр миграционных исследований; под ред. С. Артоболевского, Ж. Зайончковской. - М.: Институт географии РАН, ИНП РАН, 2004. - 212 с. 
14. Knapp T.A., White N.E., Wolaver A.M. The returns to migration: the influence of education and migration type // Growth and Change. - 2013. - V. 44. - № 4. - P. 589-607.

15. Raghuram P. Theorising the spaces of student migration // Population, Space and Place. - 2013. - V. 19. № 2. - P. 138-154.

16. ТОП-10 Ресурсов РФ. URL: https://webindex.mediascope.net/top-resources (дата обращения 30.03.2021).

17. Smith D.P., Rerat P., Sage J. Youth migration and spaces of education // Children's Geographies. - 2014. V. 12. - № 1. - P. 1-8.

18. Smith D.P., Sage J. The regional migration of young adults in England and Wales (2002-2008): a «ConveyorBelt» of population redistribution? // Children's Geographies. - 2014. - V. 12. - № 1. - P. 102-117.

Поступила 04.04.2021 г. 
UDC 314.15:325.1-053.81

\title{
ANALYSIS OF MIGRATION FLOWS OF YOUTH IN THE TERRITORY OF SUBJECTS OF THE RUSSIAN FEDERATION
}

\author{
Nadezhda S. Lebedkina1, \\ nadezhda.s.lebedkina@tusur.ru \\ Yulia K. Alexandrova², \\ jalexandrova@data.tsu.ru \\ Vera V. Orlova ${ }^{1}$, \\ orlova_vv@mail.ru \\ ${ }^{1}$ Tomsk State University of Control Systems and Radioelectronics, \\ 40, Lenin avenue, Tomsk, 634050, Russia \\ 2 National Research Tomsk State University, \\ 36, Lenin avenue, Tomsk, 634050, Russia
}

Nadezhda S. Lebedkina, senior lecturer, Tomsk State University of Control Systems and Radioelectronics.

Yulia K. Alexandrova, associate scientist, National Research Tomsk State University.

Vera V. Orlova, Dr. Sc., professor, Tomsk State University of Control Systems and Radioelectronics.

The paper introduces the analysis of migration flows of young people under the age of 35 in the territory of the constituent entities of the Russian Federation: Moscow, Nizhny Novgorod, Voronezh, Tomsk, Novosibirsk regions, Krasnoyarsk, Khabarovsk, Transbaikal and Primorsky territories. It is indicated that the characteristics posted by users in their VKontakte profiles form an array of significant sociological information. The novelty lies in identification of attractive regions and the specifics of potential migration youth groups based on data from open sources. The object area of the research is the social network VKontakte. The subject field is determined by the specifics of formation of migration flows of youth based on data from open sources in the territory of the constituent entities of the Russian Federation. The aim of the research is to study the migration flows of young people under the age of 35 in the territory of the constituent entities of the Russian Federation Methods. Using the open API «VKontakte», the data on the hometown and current place of residence of users were obtained. Open anonymized data of user profiles was used, as well as additional filtering of accounts for the presence of bots and fake profiles in order to validate the data. Results. The authors have considered in detail the directions of studying the activity of users in social networks. Special attention is paid to the significance and potential of using big data; the possibility of differentiating user groups by their activity within the technical capabilities of a particular social network is shown.

Key words: Youth, data analysis, social networks, migration flow, regional communities.

This work was supported by the Russian Foundation for Basic Research 20-011-31154 opn.

\section{REFERENCES}

1. Polovinko V.S. Analiz migratsionnykh ustanovok molodezhi g. Omska [Analysis of the migration attitudes of young people in Omsk]. Ekonomika i upravlenie narodnym khozyaystvom, 2016, no. 11 (144), pp. 43-46.

2. Galanina E.V., Akchelov E.O. A potentia ad actum: the virtual world of a video game. Historical, philosophical, political and legal sciences, cultural studies and art history. Questions of theory and practice, 2016, no. 12 (74), P. 3, pp. 45-51. In Rus. 
3. Kashnitskiy I.S., Mkrtchyan N.V., Leshukov O.V. Migratsiya molodezhi v Rossii [Migration of Youth in Russia]. Demoscope Weekly. Available at: http://www.demoscope.ru/weekly/2016/0703/demoscope703.pdf (accessed 13 January 2021).

4. Ulmyasbaeva A.O. Sovremennye tendentsii mezhregionalnoy obrazovatelnoy migratsii rossiyskoy molodezhi [Modern trends of interregional educational migration of Russian youth]. Teoriya i praktika obshchestvennogo razvitiya. Available at: http://teoria-practica.ru/rus/files/arhiv_zhurnala/2020/12/ sociology/ulmyasbaeva.pdf (accessed 13 January 2021).

5. Leshukov O.V., Lisyutkin M.A. Tendentsii razvitiya sistemy vysshego obrazovaniya v Moskve [Trends in the development of the higher education system in Moscow]. Vysshee obrazovanie segodnya, 2013, no. 10, pp. 6-17.

6. Chislennost i migratsiya naseleniya Rossiyskoy Federatsii v 2017 godu [The size and migration of the population of the Russian Federation in 2017]. Federalnaya sluzhba gosudarstvennoy statistiki. Available at: https://www.gks.ru/bgd/regl/b18_107/Main.htm (accessed 13 January 2021).

7. Gabdrakhmanov N.K. Kontsentratsiya studentov v sisteme vysshego obrazovaniya na karte Rossiyskoy Federatsii [Concentration of students in the higher education system on the map of the Russian Federation]. Vestnik Rossiyskogo universiteta druzhby narodov. Seriya «Ekonomika», 2019, vol. 27, no. 1, pp. 7-17.

8. Gabdrakhmanov N.K. Molodezhnaya migratsiya kak indikator regionalnoy attraktivnosti [Youth migration as an indicator of regional attractiveness]. Geograficheskiy vestnik, 2020, vol. 1, no. 52, pp. 96-107.

9. Sharova E.N. Migratsionnye ustanovki molodezhi Murmanskoy oblasti [Migration attitudes of young people in the Murmansk region]. Problemy razvitiya territoriy, 2015, no. 77, pp. 88-103.

10. Kiseleva A.M. Regionalnye migratsionnye protsessy: osobennosti i problemy (na primere Omskoy oblasti) [Regional migration processes: features and problems (on the example of the Omsk region)]. Sotsiologiya $i$ obshchestvo: sotsialnoe neravenstvo i sotsialnaya spravedlivost: materialy V Vserossiyskogo sotsiologicheskogo kongressa [Sociology and society: social inequality and social justice. Materials of the V AllRussian Sociological Congress]. Moscow, 2016. pp. 1212-1225.

11. Becker G.S. Investment in human capital: a theoretical analysis. Journal of Politikal Economy, 1962 , vol. 70, pp. 9-49. Available at: https://www.semanticscholar.org/paper/Investment-in-Human-Capital\%3AA-Theoretical-Analysis-Becker/1cb85895dbeb216ac78721a2239f012f8e8a9167 (accessed 13 January 2021).

12. Bekker G.S. Chelovecheskoe povedenie: ekonomicheskiy podkhod [Human behavior: an economic approach]. Moscow, GUVshE Publ., 2003. 672 p.

13. Zayonchkovskaya Zh.A. Migratsionnaya situatsiya v regionakh Rossii. Vyp. 1: Privolzhskiy federalny okrug [Migration situation in the regions of Russia. Iss. 1: Volga Federal District]. Sbornik. Tsentr migratsionnykh issledovaniy [Collection. Center for Migration Studies]. Eds. S. Artobolevsky, Zh. Zayonchkovskaya. Moscow, Institut geografii RAN, INP RAN Publ., 2004. 212 p.

14. Knapp T.A., White N.E., Wolaver A.M. The returns to migration: the influence of education and migration type. Growth and Change, 2013, vol. 44, no. 4, pp. 589-607.

15. Raghuram P. Theorising the spaces of student migration. Population, Space and Place, 2013, vol. 19, no. 2, pp. $138-154$.

16. Top-10 Resursov RF [Top-10 of The Russian Federation resources]. Available at: https://webindex.mediascope.net/top-resources (accessed 30 March 2021).

17. Smith D.P., Rerat P., Sage J. Youth migration and spaces of education. Children's Geographies, 2014, vol. 12, no. 1 , pp. $1-8$.

18. Smith D.P., Sage J. The regional migration of young adults in England and Wales (2002-2008): a «Conveyor-Belt» of population redistribution? Children's Geographies, 2014, vol. 12, no. 1, pp. 102-117.

Received: 4 April 2021. 